HID 45 (2018)

\title{
NUEVA VISIÓN DE LA RELACIÓN ENTRE FUEROS Y FAZAÑAS DEL DERECHO TERRITORIAL ${ }^{1}$
}

\author{
A NEW HYPOTHESIS ON THE RELATIONSHIP BETWEEN FUEROS \\ AND FAZAÑAS IN TERRITORIAL LAW
}

\section{LuZ VALLE Videla}

Universidad Libre de Bruselas

lvallevi@ulb.ac ORCID: https://orcid.org/0000-0001-9689-3015

RESUMEN: En este artículo se revisa la relación entre las fazañas y los fueros del derecho territorial castellano, mediante el análisis de su discurso, focalizando en los capítulos que combinan discurso hipotético, típico de fuero y discurso narrativo, típico de fazaña.

PALABRAS CLAVE: Fazañas; fueros; discurso narrativo; Libro de los fueros de Castiella; Fuero viejo de Castilla.

ABSTRACT: This paper reexamines the relationship betweeen fazañas and fueros in Castillian territorial law by adopting a discourse analysis perspective that focuses on chapters combining hypothetical discourse, typical of the fuero, and narrative discourse, typical of the fazaña.

KEYwORDS: Fazañas; fueros; narrative discourse; Libro de los fueros de Castiella; Fuero viejo de Castilla.

Las fazañas jurídicas castellanas aparecen en diferentes textos legislativos desde finales del siglo XI hasta el siglo XIV: las encontramos en forma de apéndice al final de algunas obras como es el caso de las fazañas de Palenzuela o bien, en otras, incorporadas al fuero como una norma más, como por ejemplo las que aparecen el Pseudo Ordemaniento II de Nájera.

$\mathrm{Su}$ atractivo y originalidad radican en el tipo de discurso que presentan: suelen evocar hechos delictivos que tuvieron lugar en un momento y un lugar concretos

Recibido: 23-3-2018; Aceptado: 27-4-2018; Versión Definitiva: 1-5-2018.

1. Abreviaturas utilizadas: $\mathrm{LFC}=$ Libro de los fueros de Castiella $; \mathrm{FVC}=$ Fuero viejo de Casti$l l a ; \mathrm{BNE}=$ Biblioteca Nacional Española, $A H D E=$ Anuario de Historia del Derecho Español .

Copyright: (C) Editorial Universidad de Sevilla. Este es un artículo de acceso abierto distribuido bajo los términos de la licencia de uso y distribución Creative Commons Reconocimiento-No-ComercialSinObraDerivada 4.0 (CC BY-NC-ND 4.0) 
mediante discurso narrativo, constituyendo un testimonio único de la vida cotidiana de las gentes de Castilla durante la Edad Media.

Si bien no son muy numerosas, las que se han conservado hasta nuestros días son muy significativas y permiten comprender su uso y significado, así como su evolución; por ende, se les han dedicado numerosos estudios: historiadores del derecho, historiadores y filólogos han tratado de definirlas y comprender su uso a lo largo de los siglos, lo que ha provocado que actualmente haya numerosas definiciones que, en muchos casos, divergen ${ }^{2}$. No obstante, se observa un consenso generalizado sobre su evolución, fruto de las reflexiones realizadas por el pionero Galo Sánchez ${ }^{3}$ : las fazañas, con el trascurso del tiempo, habrían sido despojadas de sus detalles anecdóticos y se transformarían en fueros. En base a esta hipótesis, el andamiaje de su significado y de su evolución se ha cimentado durante el siglo $\mathrm{XX}^{4}$. No obstante, cuando se analizan los textos en los que aparecen, se observa, con claridad, que los fueros no provienen de antiguas fazañas. Y este es el objetivo de mi estudio: quiero demostrar que esta evolución es incorrecta, dado que los foristas del derecho territorial usaban el discurso narrativo con unos fines concretos ${ }^{5}$. Esto lo haré a partir de un análisis discursivo de los capítulos narrativos tanto del LFC como del FVC. Así pues, en primer lugar, explicaré las acepciones de la palabra fazaña, para después centrarme en las jurídicas. En segundo lugar, analizaré el discurso de los fueros con partes narrativas y, para finalizar, el de las fazañas.

\section{Presentación}

La palabra fazaña es una voz antigua que significaba sentencia dada en un pleito, hazaña o refrán. Corominas explica que, desde la época de Covarrubias, se viene derivando del verbo facer, sin embargo, por dificultades fonéticas y morfológicas, fazaña no puede derivar de este verbo, sino de la voz árabe hásana que significa buena obra o acción meritoria, aunque no descarta que facer haya

2. Cito los estudios más significativos: entre los historiadores del derecho destacan los de Sánchez, 1929; García Gallo, 1934; García González, 1963 y Bermejo Cabrero, 1972. Entre los historiadores, es fundamental el estudio de Montoya Martínez, 1993. Numerosos son los filólogos y lingüistas que se han interesado en estas peculiares formas jurídicas, sin embargo, la base de todos los estudios nos la proporcionan Gómez Redondo, 1998, vol. II, pp. 89-94, Kabatek, 2004 y Funes, 2000, p. 20.

3. 1929 , pp. 263-265.

4. En los estudios de la nota precedente se retoma esta hipótesis de Galo Sánchez. Ver, asimismo, García Gallo, 1941, pp. 311-13; MacDonald, 1985, pp. 171-172; Alvarado Planas, Oliva Manso, 2004, pp. 17-28, 42-63, entre otros.

5. Desde el estudio de Aquilino Iglesias Ferreirós (1977, p. 117-118), la expresión derecho territorial acuñada por Galo Sánchez (1929) viene siendo cuestionada (véase, por ejemplo, Collantes de Terán de la Hera, 1996, p. 201), dado que no se trataba de un derecho que se aplicara en todo el territorio castellano. A pesar de esto, la utilizaré para designar el derecho recogido tanto en el LFC como en el FVC, debido a que, a nivel internacional, es la más usada. En efecto esto se puede comprobar, entre otros, en Martin (1992, p. 552), en Funes (2000, p. 14) o en O’Callaghan (2001, p. XXXI). 
influido en la forma romance, lo que explicaría los dos significados no jurídicos ya indicados: acción importante, por un lado; refrán, por otro ${ }^{6}$.

Ambos significados se pueden observar en diversos textos literarios anteriores al siglo $\mathrm{XV}^{7}$, como, por ejemplo, en el Libro de buen amor donde la palabra adquiere el significado de refrán en la estrofa 580a: Fazaña es usada, proverbio non mintroso ${ }^{8}$; o en El sacrifico de la misa de Berceo en la estrofa 202a, donde designa un hecho extraordinario: Lo que Abrahám fizo, esso fue grant fazaña 9 . Pero, ¿qué ocurre con su significado jurídico? Es menester darse cuenta de la importancia de las fazañas jurídicas, dado que son el primer testimonio que se conserva de esta palabra $^{10}$.

Galo Sánchez, especialista de las fuentes del derecho, las estudió en profundidad. Para él, tienen diferentes significados ${ }^{11}$ : cuando surgen, son declaraciones de la norma jurídica, hechas por el juez, declaraciones que se ajustan o no al derecho existente. De estas fazañas, se conserva, tan solo, la decisión correspondiente en forma de norma general, puesto que se sometían a una elaboración y perdían todos los detalles; así, la fazaña se convertía en fuero. Después, se da un segundo periodo, entre finales del siglo XII y durante todo el siglo XIII, en el que se produce un cambio sustancial en el derecho, dado que los monarcas comienzan a legislar. Los jueces dejan de crear derecho, para convertirse en aplicadores del mismo, aunque las fazañas se siguen utilizando cuando hay vacíos legales. Por último, tras el reinado de Alfonso X, pierden toda su importancia.

Otro historiador fundamental para comprender la visión actual de las fazañas jurídicas es Alfonso García Gallo ${ }^{12}$. Para él, hay una diferencia entre las fazañas del derecho territorial y las del derecho municipal. Si las últimas tienen como función confirmar el fuero y suministrar la prueba de su vigencia, las primeras son declaraciones ajustadas o no al derecho vigente, hechas con plena libertad por

6. Corominas, Pascual, 2002, vol. III, pp. 332-334. Yakov Malkiel ha estudiado este vocablo con mucha profundidad en su artículo Old Spanish Fazaña, Pa(s)traña, and Past(r)ija, (1950, pp. 135157, 244-259). Rastrea la evolución del significado de la palabra mediante una documentación muy rica y asocia su formación a la de la palabra pastraña. Sin embargo, su estudio se ha quedado un tanto desfasado, debido a las nuevas tecnologías y al descubrimiento de otros textos que incluyen fazañas.

7. Para hacerse una idea de los otros significados de la palabra fazaña, leer el artículo de Malkiel, Ibid., pp. 135-157.

8. Juan Ruiz, Alberto Blecua (ed.), 1992.

9. Berceo, Cátedra (ed.), 1992.

10. El primer testimonio que se conserva de esta palabra aparece en el Fuero de Castrojeriz, texto muy complejo en cuanto a su datación, debido a que está conformado, en primer lugar, por un fuero que data de 974. A este se le añadieron entre 995 y 1157 diferentes normas concedidas por diversos reyes y condes. Por último, entre 1234 y 1379, varios reyes confirmaron lo realizado por sus antecesores y se compiló todo en un único diploma. La palabra fazaña se usa, en una frase escrita en castellano, para aludir a las decisiones judiciales corroboradas por Alfonso VI (1072-1109). Ahora bien, todas las decisiones judiciales a las que alude están escritas en latín. Esto se puede observar en Martínez Díez, 2010. El segundo testimonio más antiguo lo conforman las ocho fazañas incluidas a modo de epílogo en el Fuero de Palenzuela. Por el momento, no se sabe con certeza si se deben atribuir a Alfonso VI (1072-1109) o a Alfonso VII (1109-1157). Ver García Gallo, 1934, pp. 522-531.

11. Sánchez, 1929, pp. 264-265.

12. García Gallo, 1936-1941, p. 310-313. 
los jueces (a partir del siglo XII) y contribuirían al desarrollo del derecho. Al ser fundamentales como precedente, se procuró conservar su recuerdo y de ahí que se anotaran las circunstancias del juicio: quiénes son los litigantes, la autoridad que juzga, etc. Pero estas indicaciones de una época concreta, con el transcurso del tiempo perdían interés y desaparecían. Las fazañas se convierten así en fuero o pura norma, sin alusión a su origen.

Aunque hasta el momento he hablado de las fazañas jurídicas en general, a partir de ahora me centraré en las del derecho territorial, dado que son el testimonio más abundante con el que contamos: hablar de fazañas territoriales es hacer alusión al derecho que empezó a redactarse en el reino castellano a partir del siglo $\mathrm{XIII}^{13}$. Hay que tener en cuenta que se conserva un total de siete textos de derecho territorial, aunque en este artículo solo hablaré de los dos principales, esto es del Libro de los fueros de Castiella (LFC) y del Fuero viejo de Castilla (FVC) ${ }^{14}$.

El LFC ha llegado hasta nosotros a través de un manuscrito del siglo XIV ${ }^{15}$ y ha sido editado en tres ocasiones: Galo Sánchez lo hizo por primera vez en 1924, Alvarado Planas y Oliva Manso, en 2005 y, por último, Maximiliano Soler Bistúe, en $2016^{16}$. En total, tiene trescientos siete capítulos presentados como fueros o/y fazañas, en los cuales se tratan asuntos muy diversos. Gracias a las referencias que reúne tanto temporales como espaciales, se suele fijar su producción en la provincia de Burgos, a mediados del siglo XIII, aunque sus leyes comprenden los reinados de Alfonso VIII (1158-1214) y Fernando III (1217/1230-1252). Con respecto a su significado, los historiadores coinciden al decir que se trata de derecho municipal, aunque hay divergencias de opinión con respecto a su ámbito de aplicación ${ }^{17}$.

La segunda y última colección extensa de derecho territorial es el FVC. Esta colección es la más compleja de todas, al presentar dos estadios en su proceso de redacción: el primero llevado a cabo en 1272 y el segundo, en 1356. Si de la primera etapa solo se conserva el prólogo, editado por Bartolomé Clavero en

13. García Gallo, 1936-1941, p. 310.

14. Además de estas dos grandes colecciones de derecho territorial, los otros textos son: Pseudo Ordenamiento II de Nájera, Fuero de los fijosdalgo y las fazañas del fuero de Castilla, Pseudo Ordenamiento de León, Fuero Antiguo de Castilla. Todos ellos compuestos por fueros y fazañas, recogidos en el FVC. Asimismo, existe una séptima colección que se caracteriza por no incluir fazañas: Devisas que an los sennores en sus vasallos. Cuando se estudia el derecho territorial, se suele incluir, además, la colección de veintiún fazañas del manuscrito 431 de la BNE, colección compuesta únicamente por fazañas de diferentes épocas, pero que, al no contener fueros, es difícil pensar que se utilizara para dirimir pleitos, de ahí que hable de siete colecciones y no de ocho.

15. En concreto hablo del manuscrito 431 de la BNE. Además de este manuscrito, se conservan diversas copias modernas (siglos XVII, XVIII y XIX) tanto en esta biblioteca como en la Academia de la Historia, en el Museo Británico de Londres y en el Archivo Municipal de Burgos; sin embargo, todas ellas procederían directa o indirectamente del manuscrito 431 de la BNE y, por lo tanto, carecerían de todo valor (Sánchez, 1981, pp. XI-IV).

16. Sánchez, Ibid.; Alvarado Planas, Oliva Manso, 2004; Soler Bistué, 2016. Además, Bares y Craddock llevaron a cabo una transcripción en microfichas en 1989.

17. Ver, entre otros, Iglesias Ferreirós, 1977, pp. 147-150; Alvarado Planas y Oliva Manso, supra, pp. 81-107. 
$1974^{18}$, de la segunda, que supone su redacción definitiva, ${ }^{19}$ se conservan cinco manuscritos: dos del siglo XIV y tres, del XVI ${ }^{20}$. Desde un punto de vista editorial, Asso y Manuel lo publicaron por primera vez en $1771^{21}$ y en 1847, esta edición fue incluida íntegramente en la colección Los códigos españoles concordados y ano$\operatorname{tados}^{22}$. Se tendrá que esperar hasta finales del siglo XX para que la crítica vuelva a estudiar los testimonios antiguos y renueve la edición de esta obra: Benjamín González Alonso, Ángel Barrios García y Gregorio del Ser Quijano lo harán en $1996^{23}$ y Javier Alvarado Planas junto con Gonzalo Oliva Manso, en 2004²4. Con respecto a su contenido, reúne doscientos treinta y siete capítulos, organizados en torno a cinco libros que se dividen, a su vez, en títulos. Además, incluye el prólogo mencionado más arriba y un epílogo con cuatro fazañas. No se sabe dónde se redactó y la razón por la cual se elaboró continúa siendo tema de debate y hay múltiples hipótesis al respecto ${ }^{25}$.

En todo caso, las fazañas del derecho territorial serían el precedente de los fueros y esta hipótesis es la más extendida entre todos aquellos que las han estudiado.

\section{FUEROS QUE PROVIENEN DE FAZAÑAS}

Tanto el LFC como FVC tienen en común estar compuestos por fueros y fazañas. Entre ambos, se ha establecido una clara diferencia: las fazañas, como ya he explicado, ofrecen todo tipo de detalles sobre unos hechos acaecidos mientras que los fueros codifican reglas que se erigen como posibilidades a partir un discurso sin un referente concreto. Desde el estudio del Galo Sánchez, cuando en un mismo fuero se combina discurso abstracto y discurso anecdótico, se suele interpretar como un error y se achaca a la impericia de los redactores: estos no supieron transformar las fazañas en fueros ${ }^{26}$. Deberían haber suprimido todos los detalles anecdóticos, hasta transformar la fazaña en una regla abstracta, pero, dado que eran demasiado torpes, descuidaron su labor y crearon capítulos en que ambos discursos aparecen juntos. Como ejemplos cita los capítulos 2 y 11 . Ahora bien, cuando se

18. Pp. 323-325.

19. Sánchez, 1929, p. 279; Iglesias Ferreirós, 1977, p. 155; Alvarado Planas, Oliva Manso, 2004, pp. 146, 214. José Manuel Pérez-Prendes piensa que esta fecha no es demasiado fiable y se interroga sobre la posibilidad de que el FVC se haya redactado durante el reinado de Enrique II (1369-1379) (1998-1999, p. 321).

20. El manuscrito 9199 de la BNE y el manuscrito 2205 de la Biblioteca de la Universidad de Salamanca, ambos del siglo XIV; los manuscritos 709 de la BNE, II-2428 de la Biblioteca del Palacio Real y X-II-12 de la Biblioteca del Escorial son del siglo XVI (Alvarado Planas, Oliva Manso, 2004, p. 241).

21. Jordán de Asso y del Río, Manuel y Rodríguez, 1771. Todas las ediciones hechas hasta los años ochenta son un calco de esta, incluso de su discurso preliminar (Pérez Martín, 1985, p. 264).

22. $1847-1851$.

23. 1996.

24. Alvarado Planas, Oliva Manso, 2004.

25. Ibid., p. 146. Ver igualmente, Morán Martín, 2009-2010, pp. 299-324.

26. Sánchez,1929, p. 275. 
analiza el capítulo 2, se ve con claridad que no hay una combinación de discursos, sino que se trata de un capítulo exclusivamente anecdótico. Seguramente se refería al capítulo siguiente, es decir, al capítulo 3, dado que este sí muestra dicha estructura: en un primer momento, aparece la norma y, a continuación, aparece un pleito relacionado con la norma. Pasa lo mismo con el capítulo 11.

Ahora bien, además de estos dos capítulos, me gustaría subrayar que este tipo de discurso se da con frecuencia no sólo en el LFC, sino también en el FVC. En el LFC, en los capítulos 3, 23, 25, 74, 88, 106, 133, 142, 149 y 181 vemos que la norma precede a la anécdota y en los capítulos 116, 151, 206, 232, 284, 290, en primer lugar, aparece la anécdota y a continuación la norma. En el FVC los capítulos 1.2.2, 1.2.4, 1.3.2, 1.5.5, 1.5.10, 1.6.4, 3.1.7, 3.1.8 y 4.2.3 responden al primer patrón, en cambio no se ha incluido ninguno que responda al segundo.

Si se analiza la forma que los redactores dan al discurso, haciendo preceder o seguir la anécdota a la norma, conjuntamente con la manera de nombrarlos, se observa algo muy llamativo: los redactores los nombran atendiendo a una pauta. En el primer caso, nos enfrentamos a fueros y en el segundo, a fazañas. Hay tres excepciones: en el LFC, el capítulo 3 no tiene ningún tipo de frase introductoria que especifique si se trata de un fuero o de una fazaña y, en el FVC, el capítulo 1.5.5 es presentado mediante la combinación de ambos términos: Esta es fazanna de fuero de Castilla. Por otro lado, en cuanto al tipo de discurso, el fuero 151 sería un fuero más del LFC de no ser porque, al principio, se nos informa de que quien juzgó fue el rey Fernando. En este apartado hablaré de los fueros que incorporan discurso anecdótico y en el siguiente, analizaré las fazañas con una parte de fuero.

Cuando se lleva a cabo un análisis de todos estos capítulos, se descubre que estos fueros no provienen de antiguas fazañas. Retomemos uno de los ejemplos dados por Alfonso García Gallo: el fuero 25 del LFC $^{27}$. En este se observa una primera parte en la que aparece la norma y una segunda, con los detalles del pleito del que procedería; es decir, la antigua fazaña. El forista decidiría eliminar todos los detalles concretos, porque las personas del pleito dejaron de interesar a sus contemporáneos, empero al ser poco diestro, su labor resulta defectuosa ${ }^{28}$ :

25. Títulos de los deudores enfermos de fiebre o de gota o de dolor.

$\left(1^{a}\right)$ Esto es por fuero de omne que demanda deuda, e dize el deudor que es enfermedat de fiebre: Deve atender fasta trenta dias, et de trenta días adelante, que cumpla de fuero al querelloso. Et si es malutia de gota o de dolor que non puede andar, que

27. 1934-1941, p. 312. Hablo de este fuero porque, todavía no he podido datar el fuero 11, dado como ejemplo por Galo Sánchez. El capítulo 3, en el que aparece el mismo tipo de discurso y que, en principio, sería el fuero al que aludiría Sánchez, se cita a un tal don Diago, referencia del todo insuficiente para datar el capítulo, pero que señala hacia la primera mitad del siglo XIII, dado que se debe referir a don Diego Lope de Haro II (†1237), como es el caso en otros fueros y fazañas del libro. Pienso esto porque se le presenta como adelantado del rey, se le sitúa en la casa del rey y juzga el pleito junto a los otros adelantados del rey. Todos los fueros que he podido datar se pueden ver en mi artículo Valle Videla, 2009.

28. Todos los textos citados en este artículo provienen de la edición realizada por Alvarado Planas y Oliva Manso (2004), al haber editado juntos tanto el LFC como el FVC. 
faga derecho al querelloso luego él, o que dé quién rrazone por él. $\left(2^{a}\right)$ Et sy fuere pleito que deva dar jura et non fuere al dia șspidel plazo de la jura, commo fuere julgado del alcalle, a Sant Andrés, alli do a fuero de jurar, que sea en tierra. Esto fue julgado en Burgos por donna Estevanía, muger de don Gunçalo Martínez de Bilforado, quel demandava partiçión Pero Doar, su hermano. Et ovo de jurar ella, e avía dolor en las piernas, e non podía andar sinon la levasen omnes o mugeres en braços; e ovo de ir a Sant Andrés al día del plazo a jurar, commo era julgado del alcalde; e fue ella a cumplir de derecho.

Con respecto a su significado vemos que, en la primera parte, se explica, primero, lo que debe hacer un acreedor y, segundo, lo que debe hacer alguien que debe dar jura. En la segunda parte, se cuenta cómo la mujer de Gonzalo Martínez fue a jurar a San Andrés. De todos los datos que nos ofrece este fuero, el más importante para mi análisis es el nombre del marido de doña Estefanía, don Gonzalo Martínez de Belorado. Este hombre me interesa, porque también aparece en el fuero 149 del LFC. Observémoslo a continuación. Solo incluyo la parte pertinente:

\section{[...] Et esto fue juzgado por don Girralte Andrés e don Bernalt Andrés, su hermano, que vendieron a don Gunçalo Martínez aquel soto de molinos de iuso la puente de Varrio de Sant Johan [...]}

Puedo afirmar que en ambos fueros se trata de la misma persona, porque en los dos aparece asociado a la ciudad de Belorado. Si en el fuero 25 se dice explícitamente, en el fuero 149 lo deducimos a partir de la referencia espacial que aparece: Gonzalo Martínez compró a los hermanos Andrés unos molinos situados en uno de los barrios de Belorado, el barrio de San Juan ${ }^{29}$. En este fuero, juzga don Lope Díaz de Haro Cabeza Brava (†1237), señor de Belorado durante el reinado de Fernando $\mathrm{III}^{30}$. El hecho de que Gonzalo Martínez aparezca junto a este noble, permite ver que se trata de un contemporáneo de Fernando III, contemporáneo, por tanto, del redactor de la colección. Esta datación también es válida para el fuero 25.

Puesto que don Gonzalo estaba vivo en el siglo XIII, es imposible que se haya incluido en los fueros por error y suponga un vestigio de la fazaña original. Si el redactor habla de él en los dos fueros, debe ser por otra razón.

Otro fuero que contradice de lleno tal evolución es el capítulo 1.2.2 del FVC. En él se nos habla de cómo debe hacer un caballero, tenedor de un castillo por el rey o por un ricohombre, cuando el territorio en el que está el castillo cambia de manos:

[...] Et, si qualquier destos rreys o de los rricosomnes fallesçiere el pleyto que pusieren, e el otro demandare los castillos al cavallero que los tiene por él, deziendo que le fallesçió el pleito, e aquel que toviere los castiellos en fialdad non ge los deve dar, mas dévelos dar al sennor cuyo natural es e quando ge los diere, ir al sennor a quien fizo el omenage por los castillos una soga a la golilla e meterse en sus manos; e puede fazer dél lo que quisiere el sennor. Et esto fue judgado por

29. Ver Gómez Villar, 2000, p. 334

30. Ver Blanco,1973, pp.131-132. 
muchos buenos rricosomnes en Castilla. Et después fue judgado por Rui Sánchez de Navarra, que tenía castillos en Navarra en fialdad por el rrey de Aragón, [...]

He destacado en negrita la parte interesante. Se trata del principio de la parte anecdótica del fuero: en un primer momento, el forista informa de que, mediante esta norma, se juzgó a muchos ricos hombres, y, después, de que, el mismo fuero se usó más tarde para juzgar a Sánchez de Navarra. Este capítulo es sumamente problemático para la hipótesis de Galo Sánchez, porque, nos muestra con claridad que, aunque el fuero se utilizó primero para juzgar a otros nobles, se prefiere ilustrar la norma con la historia de Ruiz Sánchez de Navarra. La manera en la que el forista introduce el discurso narrativo evidencia que los motivos por los cuales se incluye discurso narrativo en los fueros son otros. ¿Cuáles pueden ser? Veámoslo a continuación:

1. Se podría pensar que la parte anecdótica de los fueros 1.2.4, 1.6.4, 3.1.8 del FVC es un vestigio de la fazaña, a partir de la cual se originan; sin embargo, el hecho de que se cite al rey como fuente de la norma podría señalar en otra dirección y es que, más allá de su origen, citar a esta autoridad permitiría legitimarlas ${ }^{31}$ : el rey fue quien juzgó, las normas son, por tanto, válidas.

2. En otros casos (LFC: 23, 74, 88, 133; FVC: 1.3.8, 4.2.3), cuando se examina la anécdota y se compara con la norma, no está tan claro que aquella sea la versión primitiva a partir de la cual se realizó esta. Por lo general, ninguno de los datos que el forista incluye en la parte anecdótica permite hacerlo, dado que son muy escasos y ninguno de ellos lo prueba. ¿Por qué incorpora el nombre de las partes al final de los fueros? Podríamos estar ante otra técnica, para dar mayor autoridad a su discurso. Este pudo incluir al final de los fueros ciertos nombres clave, para corroborar lo expuesto en la norma; puesto que citar a los participantes de un juicio recordaría lo que pasó, además de demostrar que la norma ya se había utilizado para juzgar un pleito. El hecho de nombrar las partes o la autoridad bastaría para crear un diálogo implícito con sus interlocutores. El redactor eligió casos prácticos conocidos al formar parte de la memoria colectiva del lugar en que fueron juzga$\operatorname{dos}^{32}$. Sobre el tema de dar credibilidad a un discurso, es muy interesante la reflexión llevada a cabo por Marie-Claude Malenfant cuando analiza la importancia que daba Quintiliano (\$41) tanto a lo dicho como a lo hecho por un juez, por una de las partes o por el abogado de estas para persuadir a un auditorio ${ }^{33}$ :

Cette dernière catégorie, qui peut sembler étrangère à l'exemplum, s'inscrit pourtant rigoureusement parmi ses espèces puisque l'orateur donnera du crédit au point dont il veut persuader son auditoire par similitude avec un dit ou un fait déjà connus; or les paroles ou les actes des membres du procès sont pour ainsi dire

31. Para los procedimientos de legitimación de un discurso ver Charaudeau, Maingueneau, 2002, p. 86.

32. Este tema lo he abordado al estudiar la relación entre el LFC y la villa de Belorado en Valle Videla, 2009, pp. 201-219.

33. 2003, p. 37. 
immédiatement connus des auditeurs car ils sont contemporains du moment où la cause est entendue.

3. Otros muchos fueros, además de indicar el nombre de las partes al final, incluyen detalles sobre los pleitos que los erigen en verdaderos exemplos. En estos, el forista incluye información que va más allá de la simple regla enunciada al principio del capítulo, y su voz adquiere un tono didáctico que transluce diferentes intenciones: en unos casos insiste en cómo las partes, tras la sentencia, se ven obligadas a cumplirla (LFC: 25,149 ; FVC: 1.5.5, 3.1.7); a veces, da un contraejemplo que informa de las nefastas consecuencias que acarrea no respetar la norma (LFC: 106) e incluso, al dar el contraejemplo (LFC: 142), el forista se involucra con la narración y aprovecha para añadir, a partir de esta, una enseñanza jurídica; en otros casos, vemos cómo incluye aspectos de los pleitos que le permiten resaltar ciertas cualidades morales de los involucrados: en el fuero 1.2.2 nos presenta un caballero que destaca, sobre todo, por su mesura y prudencia; al igual que en el fuero 1.3.2, en el que ensalza la figura del rey al destacar que se trata de un hombre justo y dadivoso. En definitiva, los foristas adoptan un tono pedagógico y utilizan las historias de los fueros para tratar el contenido de las normas desde diferentes puntos de vista. Se podría ver en estos un récit bref donné comme véridique et destiné à être inséré dans un discours [...] pour convaincre un auditoire par une leçon salutaire, definición de exemplo homilético según Claude Bremond y Jacques Le Goff ${ }^{34}$.

4. Dentro del grupo de los fueros que incorporan anécdota al final, tres merecen una atención particular, porque contradicen de lleno la hipótesis de Galo Sánchez. Los tres incorporan elementos lingüísticos que ponen en entredicho que la anécdota suponga el origen de la norma. Hasta ahora, los fueros analizados han incorporado la anécdota mediante el verbo juzgar tras la regla abstracta. Este verbo funciona, en estos casos, como introductor de discurso referido y alude al origen jurídico de la anécdota, conectándola directamente con el fuero que aparece al principio. Sin embargo, en estos tres (LFC: 3, 181; FVC: 1.5.10), los redactores no utilizan este verbo, sino el verbo contecer. Iniciar la anécdota con este verbo le proporciona un significado diferente, por cuanto al utilizarlo el redactor insiste en que los hechos evocados han acaecido y esto es lo importante para él. La anécdota se reivindica como histórica, se da por cierta y así nos lo señala desde el principio. Además, cuando los redactores usan este verbo, introducen información en la parte anecdótica sobre aspectos de los enfrentamientos que poco tienen que ver con el juicio en sí mismo. Mediante esta técnica, lo que hacen es dirigir la atención del lector hacia lo ocurrido antes del pleito y dejar en un segundo plano el juicio: en el capítulo 3, se nos cuenta que un señor, que ha forzado a una de las mancebas que le sirven, huye de la villa para refugiarse en casa del rey y, en el fuero 181 del LFC así como en el capítulo 1.5.10 del FVC, que un señor quiere proteger a sus vasallos de una enemistad surgida a raíz de sus actos. Los redactores dan tanta

34. 1996, pp. 37-38. 
importancia a los hechos que rodean al juicio como al juicio en sí mismo e incluyen las sentencias al final, sentencias que emparentan la anécdota con la norma del principio. Una vez más, vemos, gracias a estos elementos, que la anécdota incorporada al fuero, no es una mera repetición que debió suprimirse, sino que adquiere vida propia y nutre el discurso de los fueros. Hace que estos se vuelvan más persuasivos, más reales y se aproximen con mayor facilidad a la experiencia del auditorio al que iban dirigidos.

Debido a todo esto, es inadecuado postular que los redactores de estas colecciones eran incapaces de llevar a cabo una refundición adecuada de las fuentes. Estos redactores dan muestras de perseguir un objetivo concreto cuando incorporan anécdota en los fueros.

\section{LAS FAZAÑAS Y LOS FUEROS}

Si las fazañas no son el precedente de los fueros, ¿qué relación mantienen con estos? Cuando se analiza su discurso, se puede observar que, en ellas, los fueros son fundamentales. En efecto, cuando se expresa el forista, hablan las partes o juzga la autoridad, en muchas ocasiones, citan fueros.

Un muy buen ejemplo de esto es la fazaña 249 del LFC: Fernando Ibáñez, un hombre bueno de Belorado ${ }^{35}$, se enfrenta a Mose Amordosiel, un hombre judío de Burgos. Este le pide por carta que salde la deuda que su padre contrajo con él, antes de morir. Fernando Ibáñez exige que Mose Amordosiel pruebe la deuda; pero el burgalés se niega a hacerlo, puesto que alega haberlo hecho anteriormente. Fernando Ibáñez, que parece conocer muy bien la ley, afirma delante del alcalde:

[...] dixo Ferrant Yuánnez al alcalde que non diese la carta que si non pudiese provar la carta el judío, deve perder la deuda de la carta e pechar sesenta sueldos, pues rrazonó ante el alcalde que provada auvía la carta [...]

Tras lo cual, dictamina el alcalde:

\section{[...] Et si non pudiese provar como avía provado la carta, juzgó el alcalde que provase el judío la carta de la deuda con judío e con christiano, [...]}

Si comparamos el discurso indirecto de ambos, descubrimos que los dos utilizan la misma norma; norma que el LFC también recoge. Ambos han utilizado el fuero 34 y lo citan en el juicio. Veámoslo a continuación:

Esto es por fuero: Que si judio demanda por carta alguna deuda e non la puede provar, deve tener el alcalde la otra. Et si lo pudiere provar, que aya su deuda, e

35. Ver Valle Videla, 2016, p. 425. 
peche el que niega sesenta sueldos; et si non lo pudiere provar, como lo dize la carta, sea quita la deuda, e peche sesenta sueldos el judío. [...] Et si el christiano que fizo la carta testiguare con otro judio, non cumpla; que sin el escrivano que fizo la carta deve provar con judio e con christiano.

Fijémonos primero en Fernando Ibáñez. Concretamente, cita la línea 3 y la línea 4 del fuero, parte que he destacado en negrita. El hecho de que cite el fuero muestra que lo conocía. El alcalde, en cambio, cita la última frase del fuero. El hecho de que los dos acudan a la misma norma y la citen muestra de manera clara que el fuero 34 es anterior a la fazaña. La otra posibilidad, la de contemplar que la fazaña es anterior al fuero, implica un proceso de creación mucho más complicado y menos plausible: a partir de lo dicho por ambos en el juicio, se habría creado una norma, de la cual surgiría el fuero 34. Téngase en cuenta, además, que Fernando Ibáñez aparece en otros capítulos del LFC y, en uno de ellos, lo vemos junto a los alcaldes reales de Fernando III (†1252), con lo cual esta fazaña nunca pudo ser el antecedente del fuero. Esta fazaña nos muestra de manera clara que, en las fazañas, tanto las partes como los alcaldes se valían de los fueros.

Otra fazaña muy significativa a este respecto es la 214. En este caso, se observa que una persona, probablemente originaria de Belorado ${ }^{36}$, muere por accidente en Quintanilla de Cuércedes, villa del alfoz de Cerezo ${ }^{37}$. El concejo de Quintanilla debe asumir la responsabilidad de tal muerte y pagar una multa al señor de Belorado, don Lope Díaz de Haro ${ }^{38}$. Cuando don Lope les pide que asuman su responsabilidad, el concejo se niega y le presenta los privilegios que el rey Alfonso VIII les había acordado: Et el concejo mostraron sus cartas a don Lope Díaz de Faro que tenían del rrey Alfonso que no devían dar omezidio por tal rrazón. En efecto, estos privilegios los eximían de pagar las multas en caso de que cometieran algún homicidio ${ }^{39}$. Gracias a esta fazaña descubrimos la vigencia del fuero de Cerezo en el siglo XIII.

Pero, ambas fazañas no son una excepción, puesto que se puede rastrear el uso de otros fueros en las dos colecciones. Veámoslos a continuación:

36. 2016.

37. Gonzalo Martínez Díez explica que Quintanilla del Monte pertenecía al alfoz de Cerezo durante el siglo XI, pero que, en esta época, la villa se llamaba Quintanilla de Riba de Cortizis. En 1250, ya se conocía con el nombre de Quintanilla de Cuercedes (1987, pp. 158-160). Es importante señalar, además, que este estudioso ha establecido que el Fuero de Cerezo no es un texto de 1146, sino un texto redactado durante el reino de Alfonso VIII (1982, p. 51).

38. Blanco, 1973, pp. 131-132.

39. Martínez Díez, 1982, p. 154. 
LFC

\begin{tabular}{|c|l|}
\hline 83 & $\begin{array}{l}{[\ldots] \text { un omne de allen sierra: Que demandava a Don Domingo vn moro que se }} \\
\text { viniera e alabóse ante el alcalde que lo faría suyo, así como fuero mandase. }[\ldots]\end{array}$ \\
\hline 186 & $\begin{array}{l}{[\ldots] \text { Et juzgáronles los adelantados por fuero que pues dádoles avían a partir }} \\
\text { en una heredat, que la partiçión ir devía adelante; e ouviéronles de dar en todo } \\
\text { a partir. [...] }\end{array}$ \\
\hline 206 & $\begin{array}{l}{[\ldots] \text { mandó el alcalde que diesen otra vez fiadores que recudiesen si alguno }} \\
\text { demandase por rrazón de donna Elvira, su tía, como era fuero; }[\ldots]\end{array}$ \\
\hline 207 & $\begin{array}{l}{[\ldots] \text { Et el conde demandó al conçejo quel diesen fiadores de quanto mandase }} \\
\text { el fuero; e dieron fiadores que non fizieron aquella fuerça que él dizía [... }\end{array}$ \\
\hline 210 & $\begin{array}{l}{[\ldots] \text { Et dizían los alcaldes de Burgos, don Garçía Yuánnez e don Ordonno e }} \\
\text { otros omnes buenos de Burgos que non era fuero [...] }\end{array}$ \\
\hline 276 & $\begin{array}{l}{[\ldots] \text { Et de sí sopo don Moriel en verdat que tal fuero avían los de Ojacastro; e }} \\
\text { mandól dexar e dexáronle luego e que juzgasse su fuero. [...] }\end{array}$ \\
\hline 307 & $\begin{array}{l}{[\ldots] \text { et una muger dizía que era su hermana, fija de su padre, por el fuero fízose }} \\
\text { fija por padrinos et por madrinas [...] }\end{array}$ \\
\hline
\end{tabular}

FVC

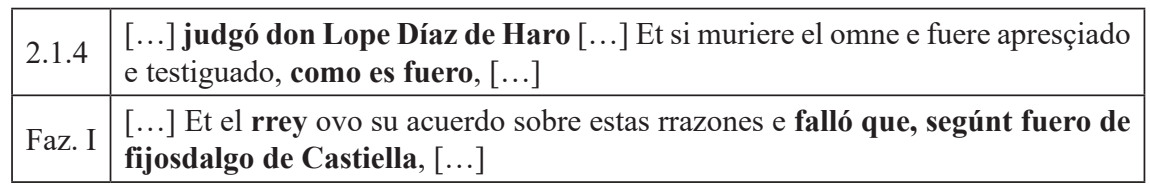

Gracias a estos ejemplos, se exterioriza la relación entre fuero y fazaña: las partes actúan en los juicios según el fuero, para que se reconozcan sus derechos. Por su parte, la autoridad muestra dos comportamientos bien diferenciados: o bien juzga a partir del fuero o bien pide que se actúe a partir de lo que manda este. En cualquier caso, los fueros son esenciales para el juicio por fazaña.

Ahora bien, la relación entre ambos no solo se hace patente en estos capítulos, también se observa en otras fazañas del LFC que incorporan discurso abstracto al final del discurso narrativo. Me refiero a las 116, 206, 232, 283 y 289. En estas, el discurso de fuero no lo profieren ni las partes ni la autoridad, sino que depende del forista que ha realizado la colección. Estas fazañas muestran a un forista preocupado por la sentencia emitida por la autoridad:

1. En la fazaña 116 en la que se cuenta un juicio por un caso de adulterio en la corte del rey Fernando III, tras la sentencia, el forista pasa a completarla a partir de otras posibilidades: analiza cuál es la pena si el marido engañado solo mata al amante de la mujer y cuál, si el marido mata tanto al amante como a la adultera.

2. En la fazaña 232, en la que se trata un juicio en el que se enfrenta un tornadizo a un cristiano por un robo, el forista, tras la sentencia dada por los alcaldes de Burgos, al igual que en la anterior, la completa a partir de otras posibilidades, en 
función de la religión de las diferentes partes y de las circunstancias que envuelven el pleito.

3. En la 283, se aborda un pleito sobre una deuda contraída por un hombre que se marcha de una villa y el acreedor exige a la esposa que la pague. Una vez más, el forista completa la sentencia dada por el alcalde, al añadir más posibilidades, a partir del comportamiento de la mujer frente al acreedor.

4. La fazaña 289 trata un problema de baraja entre dos familias. Mientras, en la parte anecdótica, el emisor evoca las causas y las consecuencias de tal enfrentamiento, así como un problema de jurisdicción a la hora de juzgarlo; en la parte abstracta, comenta diferentes aspectos relacionados con una baraja dentro de una villa. Esta última parte es mucho más amplia que en las fazañas anteriores, dado que el forista aprovecha para completar la sentencia, teniendo en cuenta otros muchos aspectos: si se destroza una casa durante la baraja, qué deben hacer los jurados si hay heridos entre los que barajan y qué deben hacer si no los hay, el dinero que debe pagar la parte que no se presenta ante la autoridad tras la baraja, etc. Sin embargo, su actitud es diferente a la de las otras fazañas porque, al final, interviene para dilucidar una parte de su discurso: [...] todas estas cosas sobreescriptas de suso que deven fazer los jurados non son por fuero, mas es postura de conçejo. Mediante esta frase, nos hace descubrir que todo lo que dice sobre el comportamiento de los jurados es una ordenanza $\mathrm{a}^{40}$ de su concejo y no un fuero; es decir que, el comportamiento de estos oficiales se adscribe a una comunidad concreta y depende por entero de esta. Así pues, cuando el forista se desvía del fuero, lo explicita.

5. La fazaña 206, en la que se evoca un pleito surgido a raíz de una herencia, también incorpora una parte de discurso abstracto, pero, esta vez, el forista actúa de manera diferente tanto por el orden que da al discurso como por su contenido. Veámosla en detalle:

Esto es por fazannia: Que don Gil e Johan Marín, su hermano, en Logronno, demandavan a don Bernalt de Limojas partiçión de donna Eluyra, su tía; e vinieron ante el alcalde e mandó el alcalde a don Gil e a Johan Marin e a Diago, su hermano, que diesen fiadores de la villa de levar la voz adelante; e partieron la heredate el mueble. Et ante que echasen suertes, mandó el alcalde que diesen otra vez fiadores que recudiesen si alguno demandase por rrazón de donna Elvira, su tía, como era fuero; e dieron fiadores de la villa et levaron su partición. Et quien provar quisiere a omne de Logronno por demanda de mueble o de heredat, dével provar con dos vezinos derechos de la villa e duennos de sus casas. Et de comienço del pleito demandavan don Gil e Johan Marin e Diago, su hermano, a don Bernalt de Limojas que metiese mueble e heredat en mano de tenedores, mas que diesen fiadores de levar la voz adelante, así como avía juzgado, e que rrazonase su pleito adelante; e de cómo ellos rrazonasen juzgaría el alcalle. Et por fuero de Logronno, si un omne de la villa firiere de cuchiello o sacare cuchiello en casa de rrey a vezino de la villa, dévenle cortar la mano; et si muriere deve pechar dozientos sueldos e ser enemigo de sus parientes del muerto.

40. Según Luis García de Valdeavellano, postura equivale a ordenanza. 1973, p. 266. 
En un primer momento, el forista evoca un pleito que tiene lugar en Belorado, aunque uno de los que reclaman la herencia vive en Logroño y la persona a la que se la reclama es un franco afincado en Logroño ${ }^{41}$. Tras explicar qué juzga el alcalde y cómo obtienen los herederos la partición, introduce un fragmento del fuero de Logroño (destacado en negrita). Este fragmento lo podemos rastrear tanto en el LFC, en el capítulo 16942; como en el propio Fuero de Logroño ${ }^{43}$. Mediante este fragmento, trata lo que debe hacer un vecino cuando quiere probar algo ante un hombre de Logroño. Tras esta glosa, vuelve de nuevo al principio del pleito; empero, esta vez es para insistir en cómo han actuado los implicados en la partición y para destacar que su manera de razonar, influirá en la decisión del alcalde. No contento con su discurso, a caballo entre la fazaña y el fuero, cierra el capítulo con otro fragmento del Fuero de Logroño ( $2^{\text {a }}$ parte destacada en negrita $)^{44}$.

Con su labor, el forista no solo nos muestra que la sentencia está emparentada directamente con el Fuero de Logroño, sino que, además, establece vínculos directos entre la fazaña, los fueros del LFC y los del Fuero de Logroño; por otra parte, evidencia que el forista consultó dicho fuero para completar esta fazaña. La lógica de la última añadidura no queda muy clara, dado que nada tiene que ver con el problema de herencia; quizá, durante el pleito, hubo un incidente con un arma blanca o quizá el forista se equivocó. En todo caso, es importante destacar que el Fuero de Logroño supone la introducción del Fuero de los francos en la Península Ibérica. Este fuero se aplicaba tanto a los franceses como a los castellanos afincados en Logroño ${ }^{45}$. El forista nos muestra a través de su discurso que, cuando el alcalde juzga por fazaña, tiene en cuenta el origen geográfico de las partes y aplica los fueros necesarios en función de esto.

Todas estas fazañas del LFC nos muestran a un forista que no se conforma con los fueros que se columbran en los pleitos, sino que necesita ir más allá, ampliando la sentencia, vinculando el caso particular a la norma general. El hecho de que las glose es una muestra clara de que estamos frente a un forista inquieto, que agota el contenido jurídico del caso concreto. Ahora bien, no se deben interpretar estos fragmentos de discurso hipotético como una muestra del proceso de simpli-

41. Esto se puede averiguar gracias al fuero 295 del LFC, dado que en él se vuelve a hablar del mismo conflicto, pero esta vez quienes se enfrentan por la herencia de doña Elvira son los dos beliforenses: Diago Girralte y don Gil González. El forista especifica que Doña Elvira es de Logroño.

42. "Esto es por fuero de Logronno: [...]Et puede prouar a cada demanda de mueble e heredat que les demanden con dos vecinos derechos e duennos desus casas.". Alvarado Planas, Oliva Manso, 2004, p. 311.

43. Fuero de Logroño: "[...] Et si alicuis homo de foris inquisierit iudicium ad ullus populator, vel ad vicino de villa, et non potuerit firmare cum duas testimonias legales, vicinos de villa, qui habeant suas casas, et suas haereditates in villa; et si ipsas testimonias non potuerit habere, audeat sua jura in Sancta Maria, Caput villae [...]", Muñoz y Romero, vol. I, 1970, p. 340.

44. Fuero de Logroño: "[...] Et ullus homo qui traxererit cultrum perdat pugno, et si non redimat se ad principe terrae, si potuerit firmare per foro de villa. Et in super de hanc populantes de ibi percuserit alium qui faciat sanguinem, pectet decem solidos medios in terra ; et si percuserit eum, et non fecerit sanguinem V solidos, meios in terra ; et si non potverit firmare audeat sua jura. [...]", Muñoz y Romero, Ibid., p. 336.

45. Gibert, 1961, p. 719, nota 51. 
ficación que postula Galo Sánchez. Cuando se estudia el discurso anecdótico de estos pleitos, se descubre que no ha sufrido modificaciones, puesto que, por un lado, ofrecen una intriga perfecta ${ }^{46}$; por otro, se presenta a las partes y la autoridad como en las otras fazañas. Es más, en dos ocasiones, el forista señala el paso del discurso narrativo al discurso abstracto mediante el marcador mas, lo que muestra claramente que para él se trata de dos partes bien diferenciadas ${ }^{47}$. En resumidas cuentas, cuando el forista combina ambos tipos de discurso, no lo hace porque ningunee los detalles anecdóticos; sino que, para él, tanto el caso concreto como la norma abstracta son fundamentales.

Pero retomando la relación entre fazaña y fuero, a partir del análisis que he realizado, es muy difícil seguir creyendo que estas son una muestra de derecho consuetudinario, basado, sobre todo, en el libre albedrío de los jueces, como se viene diciendo desde el estudio de Galo Sánchez ${ }^{48}$. Las que he analizado prueban que, cuando se juzga por fazaña, se acude a los fueros, primero, porque las partes los usan para defenderse; segundo, porque la autoridad los utiliza al juzgar; tercero, porque el forista glosa mediante fueros algunos juicios.

Asimismo, cuando se comparan las fazañas del derecho territorial con las del derecho local, es decir con las fazañas del fuero de Palenzuela o las fazañas del fuero de Castrojeriz, vemos que la diferencia entre estas y aquellas no es tan importante, sino que hay una continuidad. Gracias a los estudios realizados por Alfonso García Gallo y Gonzalo Martínez Díez se constata que las fazañas de los fueros municipales son la confirmación del fuero ${ }^{49}$. Es decir que, cuando se juzgaba por fazaña, a finales del siglo XI y principios del siglo XII, se acudía al fuero y estas se erigieron en la prueba de su aplicación. Desde mi punto de vista, las fazañas del derecho territorial se asemejan a las del derecho local: en el derecho territorial, la base de los juicios por fazaña es el fuero y estas son la prueba de su vigencia. Todo apunta, por tanto, a que estas y aquellos son dos caras de una misma moneda ${ }^{50}$.

Sea como fuere, estas nunca fueron despojadas de sus detalles anecdóticos para ser transformadas en fueros, sino que, precisamente por sus detalles, los foristas debieron utilizarlas para demostrar la validez de los fueros. Desde esta perspectiva, y una vez más, el discurso jurídico del derecho territorial muestra vínculos con los exemplos: según Quintiliano, la demostración más eficaz para probar algo es el exemplo. Este consistía en acudir al recuerdo de un hecho histórico o un hecho comúnmente admitido por todos, cuya extensión podía variar desde la mera alusión hasta una evocación con todo lujo de detalles, en función de si los hechos eran más o menos $\operatorname{conocidos}^{51}$. Las fazañas, al igual que los exemplos, reposan en los recuerdos colectivos de una comunidad específica y se-

46. La única que no respeta los principios clásicos de la organización de la intriga es la fazaña 206.

47. Ver fazañas 116 y 232.

48. Véase, por ejemplo, Pérez Martín, 1994, pp. 56-57.

49. García Gallo, 1934; Martínez Díez, 2010.

50. Definición dada por Kabateck, 2004, p. 257.

51. Explico la cita de Quintiliano a partir de Malenfant, 2003, p. 35. 
rían la prueba del vigor y la observancia del fuero al evocar conflictos jurídicos que acaecieron en un espacio concreto.

\section{Conclusión}

Las fazañas tienen varios significados y aparecen en diferentes textos medievales, sin embargo, donde encontramos el testimonio más abundante es en el derecho territorial. Galo Sánchez, pionero en el estudio de este derecho, postuló que, con el paso del tiempo, las fazañas eran despojadas de sus detalles anecdóticos y terminaban por convertirse en fueros; sin embargo, tal hipótesis no es válida cuando se analizan los capítulos que incluyen discurso narrativo tanto en el LFC como en el FVC. En efecto, a la luz de los textos, se ve con claridad, en primer lugar, que los fueros que incluyen discurso anecdótico no provienen de antiguas fazañas. En segundo lugar, que, para juzgar por fazaña, se acude a los fueros, lo que evidencia que los alcaldes no juzgaban según su libre albedrío. Por el contrario, conocían el derecho de su época y lo aplicaban cuando juzgaban por fazaña.

Cuando en el LFC y el FVC nos encontramos con capítulos cuyo discurso es total o parcialmente narrativo, no se trata de un error o de algo en devenir; por el contrario, este estudio demuestra que los foristas persiguen un objetivo y eligen utilizarlos por la riqueza de sus imágenes. No debemos olvidar que, en la Edad Media, al igual que en la Antigüedad, la memoria del pasado se componía de imágenes visuales ${ }^{52}$. Los pleitos debían provocar evocaciones compuestas de escenas que, ya fueran transmitidas o vividas, constituían una buena parte de los materiales del imaginario colectivo. Es fundamental, por tanto, revisar la anécdota de estos ordenamientos desde otra perspectiva para llegar a conclusiones definitivas sobre el derecho territorial.

\section{BibliografíA}

Alvarado Planas, Javier; Oliva Manso, Gonzalo (2004), Los fueros de Castilla: Estudios y edición crítica del Libro de los fueros de Castiella, Fuero de los fijosdalgos y las fazañas del fuero de Castilla, Fuero viejo de Castilla y demás colecciones de fueros y fazañas castellanas, Madrid.

Bares, Kathryn; Craddock, Jerry (1989), Text and Concordance of the Libro de los fueros de Castiella, MS. 431, Biblioteca Nacional, Madrid, Madison.

Berceo, Gonzalo (1992), El sacrificio de la misa, Isabel Uría Maqua (coord.); Pedro Manuel Cátedra (ed.), Obra completa, Madrid.

Bermejo Cabrero, José Luis (1972), "Fazañas e historiografía”, Hispania, 32, pp. 61-76.

Blanco, Flor (1973), Belorado en la Edad Media, Madrid.

52. Ver David, 1980, p. 73 y Carruthers, 2002, pp. 29-55. 
Bremond, Claude; Le Goff, Jacques; Schmitt, Jean-Claude (1996), L'exemplum, Turnhout.

Carruthers, Mary (2002), Le livre de la Mémoire. La mémoire dans la culture médiévale, París.

Charaudeau, Patrick; Maingueneau, Dominique (2002), Dictionnaire d'analyse du discours, París.

Clavero, Bartolomé (1974), "Behetrías, 1255-1356. Crisis de una institución de señorío y de la formación de un derecho regional en Castilla", $A H D E$, pp. 201-343.

Collantes de Terán de la Hera, María José (1996), “El delito del adulterio en el derecho general de Castilla", AHDE, pp. 201-228.

Corominas, Joan; Pascual, José A. (2002), Diccionario crítico etimológico castellano e hispánico, Madrid.

David, Jean-Michel, "Maiorum exempla sequi: l'exemplum historique dans les discours judiciaires de Cicéron", Melanges de l'École française de Rome. Moyen-Âge, Temps modernes, 92, pp.67-86.

Asso y del Río, Ignacio de; Manuel y Rodríguez, Miguel de (1771), El Fuero viejo de Castilla, sacado y comprobado con el exemplar de la misma obra, que existe en la Real Biblioteca de esta Corte, y con otros MSS., Madrid.

Funes, Leonardo (2000), "Dos versiones antagónicas de la historia y de la ley: Una visión de la historiografía castellana de Alfonso X al Canciller Ayala", Ward, Aengus. Teoría y práctica de la historiografía hispánica medieval, Birmingham, pp. 8-31.

García Gallo, Alfonso (1934), “Una colección de fazañas castellanas del siglo XII”, $A H D E, 11$, pp. 522-529.

García Gallo, Alfonso (1936-1941), “Textos de derecho territorial castellano", AHDE, 13, pp. 308-396.

García González, Juan (1963), "Notas sobre fazañas”, AHDE, 33, pp. 609-624.

García de Valdeavellano, Luis (1973), Curso de historia de las instituciones españolas, Madrid.

Gibert, Rafael (1961), "El derecho municipal de León y Castilla”, AHDE, 31, pp. 695-753.

Gómez Redondo, Fernando (1998), Historia de la prosa medieval castellana. Vol. I La creación del discurso prosístico: El entramado castellano, Madrid.

Gómez Villar, Rufino (2000), Belorado y su comarca. Economía, sociedad y vida cotidiana 1700-1813, Pamplona-Iruña.

González Alonso, Benjamín; Barrios García, Ángel; Del Ser Quijano, Gregorio (1996), El Fuero viejo de Castilla. Consideraciones sobre la historia del derecho de Castilla (c.800-1356), Valladolid.

Iglesia Ferreirós, Aquilino (1977), "Derecho municipal, derecho señorial, derecho regio", Historia, Instituciones y Documentos, 4, pp. 115-197.

Kabatek, Johannes, (2004), “Tradiciones discursivas jurídicas y elaboración lingüística en la España medieval", Cahiers d'Études Hispaniques Médiévales, 27, pp. 249-261. 
MacDonald, Robert A. (1985), "Law and Politics: Alfonso's Programan of Political Reform", Robert I. Burns, The worlds of Alfonso the Learned and James the Conqueror, New Jersey, pp. 150-202.

Malenfant, Marie-Claude (2003), Argumentaires de l'une et l'autre espèce de femme. Le statut de l'exemplum dans les discours littéraires sur la femme (15001550), Quebec.

Malkiel, Yakov (1950), “Old Spanish Fazaña, Pa(s)traña, and Past(r)ija”, Hispanic review, 18, pp. 135-57 y 244-59.

Martin, George (1992), Les juges de Castille. Mentalités et discours historique dans l'Espagne médiévale, Paris.

Martínez Díez, Gonzalo (1982), Fueros locales en el territorio de la provincia de Burgos, Burgos.

Martínez Díez, Gonzalo (1987), Pueblos y alfoces burgaleses de la repoblación Valladolid.

Martínez Díez, Gonzalo (2010), Los fueros de Castrojeriz, Burgos.

Montoya Martínez, Jesús (1993), "Mostrar por buena palabra, o por buen exemplo o por buena fazaña (Partida segunda, título IX, ley 30)", Antiqua et nova Romania: Estudios lingüisticos y filológicos en honor de José Mondéjar en su sexagenario aniversario, Granada, pp. 407-18.

Morán Martín, Remedios (2009-2010), “¿De la autonomía a la dispersión? Una hipótesis sobre la evolución del derecho señorial", IVS FVGIT. Revista de Estudios Histórico-Jurídicos de la Corona de Aragón, 16, pp. 299-324.

Muñoz y Romero, Tomás (1970), Colección de fueros municipales y cartas pueblas de los reinos de Castilla, León, Corona de Aragón y Navarra, Madrid.

O'Callaghan, Joseph F., (2001), "Alfonso X and the Partidas", Burns, Robert I., Las Siete Partidas. The Medieval Church. The World of Clerics and Laymen, Philadelphia, pp. XXX-XL.

Pérez Martín, Antonio (1985), "El estudio de la recepción del derecho común en España”, Cerdá y Ruiz-Funes, Joaquín; Salvador Coderech, Pablo, Seminario de historia del derecho y del derecho privado. Nuevas técnicas de investigación, Barcelona.

Pérez Martín, Antonio (1994), "Derecho común, derecho castellano, derecho indiano", Revista internazionale di Diritto Comune, 5, pp. 43-89.

Pérez-Prendes, José Manuel (1998-1999), "La frialdad del texto. Comentario al prólogo del Fuero viejo", Cahiers de lingusitique hispanique médiévale, 22, pp. 297-324.

Rivadeneyra (1847-1851), Los códigos españoles concordados y anotados, Madrid. Ruiz, Juan (1992), Libro de buen amor, Alberto Blecua (ed.), Madrid.

Sánchez, Galo (1929), "Para la historia de la redacción del antiguo derecho territorial castellano", AHDE, 6, pp. 260-328.

Sánchez, Galo (1981), Libro de los fueros de Castiella, Barcelona.

Soler Bistué, Maximiliano (2016), Libro de los fueros de Castiella y otros textos del manuscrito 431 de la Biblioteca Nacional de España, Buenos Aires. 
Valle Videla, Luz (2009), "Los elementos concejiles en los capítulos anecdóticos del Libro de los fueros de Castiella", Javier Alvarado Planas, El municipio medieval: nuevas perspectivas, Madrid, pp. 201-219.

Valle Videla, Luz (2016), “Antroponimia y representación en el Libro de los fueros de Castiella", García de Lucas, Cesar; Oddo, Alexandra, Magister dixit. Mélanges offerts à Bernard Darbord, París, pp. 419-433. 